\title{
APLICATIVOS DE MUSCULAÇÃO COMO DISPOSITIVOS BIOPOLÍTICOS DE EDUCAÇÃO DO CORPO' ${ }^{1}$
}

\author{
APLICATIVOS DE MUSCULACIÓN COMO DISPOSITIVOS BIOPOLÍTICOS PARA \\ LA EDUCACIÓN CORPORAL
}

BODYBUILDING APPS AS BIOPOLITICAL DEVICES FOR EDUCATING THE BODY

Carleane SOARES ${ }^{2}$

Filipe Santos RIBEIRO ${ }^{3}$

Fabio $\mathrm{ZOBOLI}^{4}$

RESUMO: O presente ensaio tem como objetivo interpelar os aplicativos de musculação como espaços contemporâneos de educação do corpo na medida em que atuam como dispositivos biopolíticos de controle e produção de corpos padronizados. Para sustentar tal argumento reflexionamos a partir de dois aplicativos de musculação que se enquadram na categoria denominada "saúde e fitness"; são eles: "BodBot Personal Trainer" e "Exercícios em Casa - Sem Equipamentos". Concluímos que esses dispositivos têm poderes apelativos que visam à homogeneização das condutas corporais, à normalização do corpo e o governo de si. Ou seja, grosso modo, são dispositivos biopolíticos.

PALAVRAS-CHAVE: Educação do corpo. Aplicativos de musculação. Biopolítica.

RESUMEN: Este ensayo tiene como objetivo cuestionar los aplicativos de musculación como espacios contemporáneos para la educación del cuerpo en la medida en que actúan como dispositivos biopolíticos para el control y producción de cuerpos estandarizados. Para mantener tal argumento reflexionamos desde dos aplicativos de musculación que entran en la categoría denominada "salud y fitness"; son: "BodBot Personal Trainer" y "Ejercicios en casa - Sin equipo". Concluimos que estos dispositivos tienen poderes atractivos que tienen como objetivo homogeneizar la conducta corporal, normalizar el cuerpo y el autogobierno. En otras palabras, hablando a grandes rasgos, son dispositivos biopolíticos.

PALABRAS CLAVE: Educación corporal. Aplicativos de musculación. Biopolítica.

${ }^{1}$ Este artigo foi apoiado com recursos do Programa de Pós-Graduação em Educação (PPGED) da Universidade Federal de Sergipe (UFS), do Programa de apoio ao Pesquisador à Pós-Graduação (Proap) e da Coordenação de Aperfeiçoamento de Pessoal de Nível Superior (Capes).

2 Universidade Federal de Sergipe (UFS), São Cristóvão - SE - Brasil. Mestranda no Programa de PósGraduação em Educação (PPGED/UFS). ORCID: https://orcid.org/0000-0002-9173-0708. E-mail: inkarli@hotmail.com

${ }^{3}$ Universidade Federal de Sergipe (UFS), São Cristóvão - SE - Brasil. Graduando no Curso de Licenciatura em Educação Física da UFS. ORCID: https://orcid.org/0000-0002-4682-5177. E-mail: filiperibeiro1803@gmail.com ${ }^{4}$ Universidade Federal de Sergipe (UFS), São Cristóvão - SE - Brasil. Professor do Programa de Pós-graduação em Educação da Universidade Federal de Sergipe (PPGED/UFS). Doutorado em Educação (UFBA). ORCID: https://orcid.org/0000-0001-5520-5773.E-mail: zobolito@gmail.com 
ABSTRACT: This essay aims to question bodybuilding apps as contemporary spaces for body education as far as they act as biopolitical devices for the control and production of standardized bodies. To support this argument, we reflect on two bodybuilding apps that fall into the category called "health and fitness"; they are: "BodBot Personal Trainer" and "Exercícios em Casa - Sem Equipamentos" (Home Exercises - Without Equipment). We conclude that these devices have appealing powers that aim at the homogenization of corporal behaviors, the normalization of the body, and the government of the self. That is, roughly speaking, they are biopolitical devices.

KEYWORDS: Body education. Bodybuilding apps. Biopolitics.

\section{Introdução}

$\mathrm{O}$ argumento que queremos sustentar neste ensaio é de que os aplicativos de saúde móvel (mHealth) 5 aqui representados por dois aplicativos de musculação ("BodBot Personal Trainer - Instrutor de treinamento" e "Exercícios em Casa - Sem Equipamentos") são dispositivos biopolíticos de controle e produção de corpos "padronizados". Como nos lembra Esposito (2017), cada vez mais o horizonte político contemporâneo está marcado por decisões biopolíticas, que com base em saberes e tecnologias avançadas, definem e conformam formas de vidas, tanto em escala individual como social. Nesta perspectiva, os dois aplicativos de práticas corporais selecionados se enquadram nesse campo e por este motivo debruçaremos a nossa análise sobre eles. Pretendemos com este escrito interpelar a educação do corpo a partir de um olhar voltado para o presente, objetivando "desmistificar" a ideia de "verdade" e preocupação com a saúde do usuário produzida a partir do discurso sobre o corpo nos aplicativos de ginástica.

Deste modo, o presente escrito parte do pressuposto de que nas ciências humanas e sociais - logo, na Educação - não se pesquisam corpos, mas sim o corpo no contexto de suas práticas, no contexto dos seus usos sociais. Pretender investigar "corpos" em detrimento de suas práticas significa reduzi-lo ao seu lado natural e físico, é colocar sua biologia à frente do social incorporado, é confundir o natural com o naturalizado (GALAK, 2014). Ou seja, o corpo só pode ser objeto de estudo da Educação a partir de suas práticas que o tomam como campo empírico sob a forma de fenômenos recortados destas práticas culturais humanas. Este escrito também se sustenta no conceito de "práticas corporais" com a intensão de não reduzir o corpo a uma episteme biologicista que o mira única e exclusivamente pelas ciências

${ }^{5}$ Embora não exista, segundo a Organização Mundial da Saúde (World Health Organization), uma definição padronizada, pode-se entender saúde móvel como a oferta de serviços médicos e/ou de Saúde Pública que se valem do apoio tecnológico de dispositivos móveis, como telefones celulares, sensores e outros equipamentos vestíveis (noutras palavras, dispositivos diretamente conectados ao usuário).

RPGE- Revista on line de Política e Gestão Educacional, Araraquara, v. 25, n. 3, p. 2475-2492, set./dez. 2021. e-ISSN: 1519-9029 DOI: https://doi.org/10.22633/rpge.v25i3.15467 
naturais/biomédicas. Sendo assim, entendemos o termo a partir de Crisorio (2015, p. 34) que expõe a seguinte reflexão: “[...] nós nos utilizamos do termo práticas corporais para significar um corpo que nunca pode separar-se de sua prática, ele que nunca pode ser reduzido a um substrato natural ou a um princípio substancial, seja físico ou biológico".

Pensar o corpo sob o conceito de "educação do corpo" se faz central na abordagem que faremos neste texto. Para compreendermos o sentido de educação do corpo precisamos revisitar o clássico conceito de técnicas corporais de Marcel Mauss. Por "técnicas corporais", Mauss (2015, p. 385) entende "as maneiras como os homens, de sociedade a sociedade, de uma forma tradicional, sabem servir-se de seu corpo". Nas técnicas do corpo culturalmente transmitidas estão inscritos discursos políticos e sentidos estéticos, assim, "educar um corpo" é transmitir a ele modos políticos e sentidos estéticos (GALAK, 2014).

Antes de adentrarmos as questões mais específicas deste ensaio, vale ressaltar que na contemporaneidade existe uma obsessão crescente em modelar o corpo, em ter um corpo "saudável" e "bonito". Deste modo, há uma enorme procura por programas de práticas corporais e por um sem-fim de dispositivos que prometem o alcance deste "corpo". No entanto, toda essa preocupação excessiva contrasta (de modo quase paradoxal) com o fato de que o corpo continua sendo um objeto desvalorizado. "Desvalorizado" porque a maior atenção dedicada a ele e às inúmeras práticas as quais ele é submetido apenas solidificam e reforçam o seu controle; parece que o corpo permanece um simples consumidor de bens e serviços, submetido a um regime de poder. Dessa forma, diante de uma sociedade neoliberal questionamos: O que seriam então os aplicativos de ginástica, se não espaços de dominação e controle, ou seja, dispositivos biopolíticos contemporâneos?

Aqui entendemos dispositivo como "[...] qualquer coisa que tenha de algum modo a capacidade de capturar, orientar, determinar, interceptar, modelar, controlar e assegurar os gestos, as condutas, as opiniões e os discursos dos seres viventes" (AGAMBEN, 2009, p. 40). Consequentemente, o autor afirma que na condição de dispositivos, estes sempre são responsáveis por produzir um sujeito. O sujeito seria então, o resultado da relação do corpo a corpo entre os viventes e os dispositivos (AGAMBEN, 2009).

Os aplicativos de práticas corporais de musculação - assim como todos os demais aplicativos que gestam comportamentos frente aos usos políticos do corpo - constituem-se em estratégias que tem no corpo seu objeto de disciplina, governo e regulação em nome da saúde, da vitalidade e da vida. Estes aplicativos cada vez mais fazem parte da vida das pessoas e atuam na produção e disseminação de regimes de verdades sobre o corpo e sobre como viver 
a vida, atuando tanto de modo individualizante quanto massificador (como dito anteriormente).

A utilização de softwares do tipo aplicativo é uma prática que se tornou muito recorrente nos últimos anos. Segundo dados da eMarketer $^{6}$, com a pandemia da COVID-19, empresas de condicionamento físico em casa, ganharam popularidade na medida em que os indivíduos se voltaram para a tecnologia móvel para receber assistência relacionada à saúde. Analisando a plataforma, observamos que o Brasil ocupa a $4^{a}$ posição no ranking de países que mais utilizam smartphones no mundo. Logo, com o aumento do uso dos smartphones, acreditamos que seja necessário a realização de mais estudos, em especial acerca dos aplicativos que se propõe orientar as práticas corporais, visto que, é uma forma de contribuir com o diálogo no campo da pesquisa não só da Educação, mas de outras áreas.

Para lograr o já anunciado objetivo deste ensaio, organizamos o mesmo a partir de mais outras três sessões para além dessa introdução que recorta o objeto e apresenta alguns conceitos chaves de nosso estudo. Na segunda parte apresentamos os dois aplicativos de musculação "BodBot Personal Trainer - Instrutor de treinamento" e "Exercícios em Casa Sem Equipamentos" para na terceira sessão interpelar os mesmos como dispositivos biopolíticos de educação do corpo. Na quarta e última parte tecemos nossas considerações finais.

\section{Sobre os aplicativos "BodBot personal trainer" e "Exercícios em casa - sem equipamentos"}

Atualmente, não há como negar que o funcionalismo dos aplicativos é imensurável; existem aplicativos para diversos tipos de necessidades e categorias como: jogos, músicas, educação, saúde e fitness, entre outros. Nascimento, Martins e Victer (2013, p. 5) entendem aplicativo para dispositivo móvel como:

[...] aplicativos, conhecidos genericamente como apps, são softwares que carregam nos aparelhos eletrônicos funcionalidades específicas para facilitar certas aplicações existentes ou novas atribuídas como por exemplo, a de um aparelho celular que além das funções originais de fazer e receber chamadas também exibe vídeos e serve como leitor de livros.

O advento e a profusão cada vez maiores desses aplicativos contribuíram para a formação de novos campos de saberes, como, por exemplo, é o caso da saúde móvel

${ }^{6}$ A eMarketer é uma empresa de pesquisa de mercado baseada em assinatura que fornece percepções e tendências relacionadas a marketing digital, mídia e comércio. Para maiores informações acessar: https://www.emarketer.com/.

RPGE- Revista on line de Política e Gestão Educacional, Araraquara, v. 25, n. 3, p. 2475-2492, set./dez. 2021. e-ISSN: 1519-9029 
(mHealth), que consiste no uso de tecnologias de computação e comunicação móveis como: telefones celulares, sensores e equipamentos vestíveis $^{7}$ que são utilizados para cuidados pessoais de saúde, para uso de instituições privadas e para programas e ações de saúde pública (WHO, 2011).

Neste ensaio, os aplicativos selecionados se enquadram na categoria denominada "saúde e fitness"; são eles: "BodBot Personal Trainer" e "Exercícios em Casa - Sem Equipamentos". Ressaltamos que ambos os aplicativos funcionam como ferramentas portáteis que disponibilizam coleções de treinos baseadas em dados digitais que auxiliam os usuários na reconstrução do "corpo" sem sair de casa. Esses aplicativos destinados para a educação do corpo são dedicados à extração e registro de informação sobre múltiplos aspectos corporais dos usuários. Também apoiados no discurso de vida saudável, conhecimento e controle de si, esses aplicativos se apresentam como aliados no gerenciamento dos cuidados com o corpo, na otimização de tarefas e na percepção ampliada sobre os hábitos e padrões de atividade física mediante análises algorítmicas. Assim, eles operam estabelecendo associações entre os corpos, algoritmos e desenvolvedores, prometendo orientação individual e previsão de cenários futuros de acordo com os corpos de agora.

Para Sant'anna (2001), entre outras formas de interferência sobre o corpo, as tecnologias voltadas para a ideia da promoção da saúde, tornaram-se tendências e atualmente ocupam as mídias banalizando de certa forma a vida humana: Nessa perspectiva:

[...] reconstruir o próprio corpo com a ajuda dos avanços tecnológicos e científicos - cosméticos, cirurgias, uso de próteses, ginásticas, regimes etc. para ganhar mais saúde e juventude não deixa de ser uma promessa fascinante a diversas épocas da civilização, mas foi na atual que ela conseguiu conquistar um espaço inédito na mídia e uma banalização importante no cotidiano, tanto das grandes quanto das pequenas cidades (SANT'ANNA, 2001, p. 18).

Dito isto, questionamos: De que corpo necessita determinada configuração espaçotemporal de saberes e poderes? Segundo a autora, há diferentes modos de compreender a consolidação dessa configuração ou tendência, uma delas expressa as ambições do homem de conhecer, controlar o corpo e, ao mesmo tempo, os limites e as fragilidades; exercendo uma espécie de gerência política sobre ele. Como o corpo é capturado, através dos discursos produzidos por esses aplicativos, trata-se então de sondar a complexidade aí embutida.

${ }^{7}$ Deborah Lupton $(2012 ; 2014)$ defende em seus textos que há uma gama crescente de objetos vestíveis que incrementam o monitoramento dos indivíduos e utilizam aplicativos da área da saúde, como calçados, roupas ou aparelhos embutidos com sensores e até pequenas câmeras equipadas para tirarem fotos automaticamente durante o dia. 
O "BodBot” é um aplicativo desenvolvido por uma empresa Norte-americana, propõe ser um personal trainer digital capaz de elaborar treinos personalizados de acordo com a capacidade do usuário e está disponível para Android e iPhone (iOS). O aplicativo possui ainda a função "nutrição", que registra as preferências alimentares do usuário, e faz sugestões nutricionais para o alcance do objetivo cadastrado. A Google Play ${ }^{8}$, o-define como:

O BodBot é um verdadeiro personal trainer digital, que cria treinos sob medida considerando seus recursos, capacidade física, dificuldade desejada e vários outros fatores. Cada treino é personalizado em cada exercício individual, e o planejamento muda com o tempo à medida que você conclui ou pula treinos. Assim como um bom personal trainer, personalizamos seu programa de treinos (GOOGLE PLAY, 2021a, grifo nosso).

Um fato que nos chamou a atenção na análise deste aplicativo, diz respeito a como o discurso presente na descrição é direcionado. Nota-se uma espécie de força retórica na escrita, capaz de induzir estrategicamente o indivíduo a adesão imediata, ou seja, o desenvolvedor se empenha a nível máximo em capturar todos, desde o primeiro contato com o aplicativo, dado que este promete cuidados específicos para cada um dos seus usuários, mesmo aqueles com algum tipo de "limitação", ou os que nunca tiveram contato com alguma prática antes. Vejamos:

[...] movimentação limitada nos ombros? Podemos corrigir isso. Os músculos das costas são menos desenvolvidos do que os do peito? Cuidamos disso também. Músculos posteriores da coxa muito rijos? Quer desenvolver os bíceps ou glúteos? Só pode treinar em pequenos intervalos de tempo durante a semana? O BodBot te ajuda com tudo isso, e seus treinos serão montados para atender suas necessidades. Nos empenhamos em disponibilizar a você o melhor programa de treinos possível, e os melhores exercícios. Mais do que isso, se você pular um treino ou decidir caminhar, incluiremos essa informação e atualizaremos seu programa para adequá-lo às mudanças. O programa vive e respira com você e por você (GOOGLE PLAY, 2021a, grifo nosso).

No caso do aplicativo "Exercícios em Casa - Sem Equipamentos", é desenvolvido por uma empresa Asiática, este oferece miniaulas de ginástica para ajudar o usuário a praticar atividades físicas sem precisar de equipamentos convencionais de academia. Os treinos utilizam movimentos com o próprio corpo e são exibidos com ilustrações e vídeos demonstrativos. O aplicativo também está disponível para Android e para iPhone (iOS). Os treinos disponibilizados pelo aplicativo são separados por grupos musculares e são divididos entre as categorias iniciante, intermediário e avançado, o que determina o tempo e a 
intensidade dos exercícios. Cada opção é responsável de mostrar ao usuário os exercícios que devem ser realizados por ele através de ilustrações animadas, descrição em texto, áudio e um link para um vídeo demonstrativo. Esses vídeos não são reproduzidos dentro da própria plataforma - o link direciona o "aluno" para uma aula produzida por terceiros em um outro aplicativo. O aplicativo também tem treinos especiais que podem ser destravados assistindo vídeos de publicidade. Sobre o aplicativo Exercícios em Casa - Sem equipamentos a Google play diz:

Treino em casa fornece rotinas de treino diárias para os principais grupos musculares. Com apenas alguns minutos por dia, você poderá definir seus músculos e manter-se em forma em casa sem ter que ir à academia. Nenhum equipamento ou treinador é necessário, todos os exercícios podem ser realizados apenas com o peso o seu corpo (GOOGLE PLAY, 2021b).

Destacamos na observação desse aplicativo, além do apelo no uso da linguagem verbal escrita, como semelhante ao anterior, há forte utilização das imagens. Estas nos chamaram atenção, tendo em vista que são imagens de corpos que na sociedade atual são tidos como "bons", como o "padrão a ser atingido". Mas, o que é o "bom corpo"? Seria os da imagem? Vejamos na figura 1:

Figura 1 - Imagem dos corpos utilizados como modelo no aplicativo

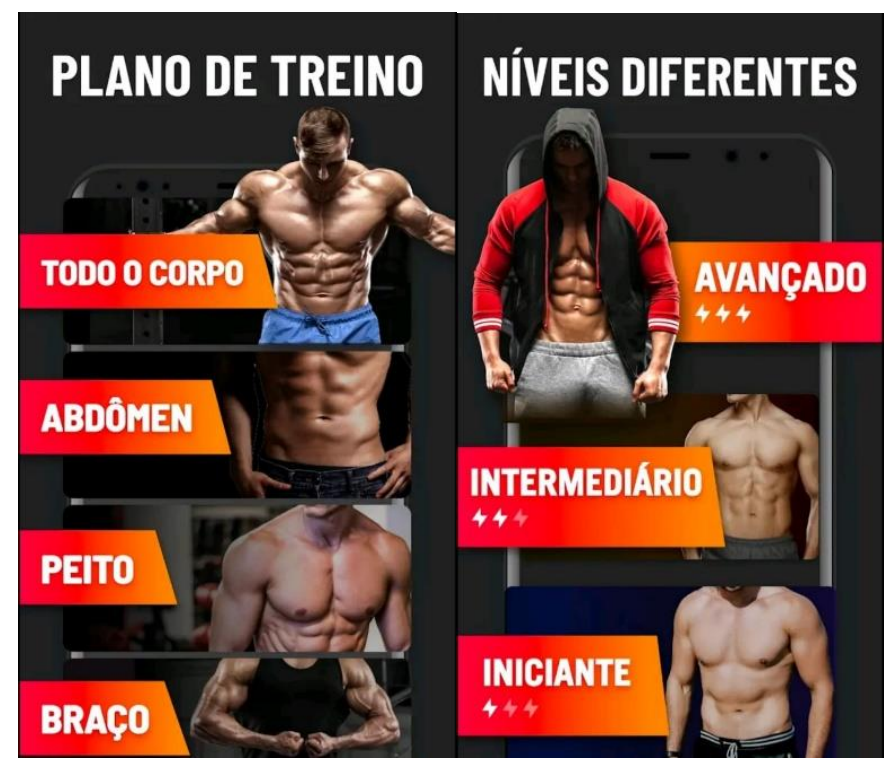

Fonte: Google play (2021b)

Pretendemos desenvolver algumas reflexões mais aprofundadas no tópico mais adiante. Por agora, vale dizer que torna-se pertinente analisar as formas pelas quais esses aplicativos para dispositivos móveis têm atuado no âmbito da educação do corpo em seu 
sentido amplo (GALAK, 2014; GOMES, 2019), seja em espaços formais (escola, hospitais, unidades básicas de saúde) ou espaços não-formais, tendo em vista que no contemporâneo, como argumenta $\operatorname{Vaz}(2003$, p. 7), “[...] é importante pensar a educação do corpo nesse contexto mais amplo em que se estruturam os cuidados com o corpo no mundo contemporâneo; afinal o corpo é educado nas escolas [...] mas também nas ruas, tevês, nas revistas ilustradas".

\section{Os aplicativos como dispositivos biopolíticos de educação do corpo}

Na sua obra "Corpo e Sentido" José Bártolo faz uma leitura intersemiótica dos processos de significação do corpo associados a práticas e aos discursos. Na concepção do autor, todo saber é produzido dentro de um sistema de comunicação, de signos e todo poder se exerce a partir da extração, apropriação, distribuição ou retenção de um saber. Segundo ele:

A um determinado regime de signos estará sempre associado um determinado regime de poder, que é antes de mais, poder semiótico: poder de fazer sentido. O poder de fazer sentido que se exerce sobre um determinado corpo exerce sentido em vista objectua-lo, torná-lo objecto, modelá-lo de acordo com uma construção de sentido particular. É a esta dinâmica de produção de sentido relacionada com um determinado poderfazer e poder-saber que nós designamos por produção associando-a à acção de uma determinada máquina semiótica (BÁRTOLO, 2007, p. 52).

Entendendo o corpo enquanto um campo de produção de sentido, como concebe o autor acima citado, parece ser impossível projetar de forma antecipada um esquema de reconhecimento, sentido ou classificação fora do corpo. Desse modo, os estudos que tratam dos signos na relação com a cultura nos mostram que é no próprio corpo, naquilo que tem de irredutivelmente único, que é possível visualizar os modos de agenciamento e as singularidades que o fazem significar (BÁRTOLO, 2007).

Todavia, se educar o corpo é transmitir a ele modos políticos e sentidos estéticos como sugere Galak (2017), a nossa pretensão é analisar como os aplicativos de musculação, enquanto dispositivos biopolíticos, concebem e significam os discursos sobre o corpo a partir de lógicas próprias do modo de "educar" esses corpos. Isso nos leva a compreensão de que os aplicativos "BodBot Personal Trainer" e "Exercícios em Casa - Sem Equipamentos”, tomam o corpo como objeto e se encarregam pela transmissão das "técnicas corporais", no sentido utilizado pelo sociólogo e antropólogo francês Marcel Mauss. Tensionar o uso desses dispositivos tecnológicos, sob a perspectiva da biopolítica é tentar desmobilizar alguns discursos que encerram o corpo na noção mecanicista. 
Logo, seria importuno, ou talvez "afrontoso" demais afirmar que não caberia a eles a responsabilidade pela gerência política e estética do "corpo a ser educado". Ou, seria? É o discurso produzido por esses aplicativos que nos interessa. Portanto, é realizando uma observação mais minuciosa nos próprios aplicativos, que talvez seja possível visualizar os modos de agenciamento e as operações exercidas sobre o corpo, que objetivam de alguma maneira a sua instrumentalização, para um determinado fim: adequação, padronização.

Doravante, entendemos que o corpo não existe fora da política, fora da palavra. Dessa forma, "volver el cuerpo un objeto de estudio es darle palabra a ese lenguage, es hacer hablar los sentidos coyunturales outorgados a las maneras como se conciben los sujetos y la política" (GALAK, 2014, p. 357, grifo nosso). Assim, "saber do corpo", "sobre o que educar sobre o corpo" para além da ideia que parece reduzi-lo a categoria de organismo, é compreendê-lo dentro da trama social por onde transitam os sentidos, já que, tratamos do corpo falante de seres falantes, do corpo "que fala". Como vimos, é de um saber que se trata, e, este saber nos leva a refletir sobre as dimensões do político e da política relacionadas a educação do corpo. Logo, a política "es asunto de cuerpos hablantes, porque no hablarían si no tuvieran cuerpo. Pero, a su vez, si tuvieran solo cuerpos y no hablasen, no tendrían necesidad de política" (MILNER, 2013, p. 12, grifo nosso).

Continuamente, pensar a política voltada para a educação do corpo é entendê-la enquanto dispositivo de manobra que utiliza os processos de ensino/aprendizagem para o controle e formação de subjetividades específicas (GALAK, 2017). Neste sentido, olhar para as técnicas/tecnologias e para os discursos produzidos por estes, implica considerar antes de tudo, o entendimento dos arranjos entre entidades distintas, de modo que o caráter "técnico" revela-se inserido em uma agenda política. Assim, entendemos que "educar o corpo" numa visão biomédica, a qual se pauta os desenvolvedores desses aplicativos, é compreendê-los como recursos de controle biopolíticos.

Ademais, em um cenário de ascensão das novas tecnologias em que o corpo, torna-se cada vez mais matéria manipulável, é preciso encarar essas "verdades" produzidas pelas plataformas digitais para perceber os modos como esses saberes e práticas vem construindo sentido e perpetuando relações de poder no seio da sociedade, sobre o que pode o corpo. Pois como nos lembra Bártolo (2007), onde se encontra um corpo dever-se-á encontrar também uma rede de relações instrumentais, uma série em funcionamento, de operadores epistêmicos, uma lógica de produção de sentidos, de um determinado sentido legitimador da rede de relações, do funcionamento dos operadores, do próprio procedimento das lógicas produtivas. 
Apesar do verbo "educar" ser um objeto muito presente, a educação corporal não está restrita apenas ao ambiente escolar com suas particularidades.

Juntando-se a isso, a ideia de controle e gestão dos corpos via estabelecimento de regras, ganha força na modernidade e se faz presente nos estudos de Michel Foucault (2005; 2008a; 2008b; 2013). A análise que o filósofo francês realiza a respeito das relações e tecnologias de poder sobre o corpo, traz à tona os conceitos de biopoder e biopolítica para os debates e as discussões sobre as diferentes estratégias para o controle, regulação e educação do corpo. Em sua genealogia, Foucault nos leva ao entendimento de que este período histórico em especial, foi responsável por instaurar políticas específicas de controle e regulação dos corpos, inclusive no sentido de criar um poder disciplinar dominante. Em termos foucaltianos:

Forma-se então uma política das coerções que são um trabalho sobre o corpo, uma manipulação calculada de seus elementos, de seus gestos, de seus comportamentos. O corpo humano entra numa maquinaria de poder que o esquadrinha, o desarticula e o recompõe. Uma 'anatomia política', que é também igualmente uma 'mecânica do poder', está nascendo, ela define como se pode ter domínio sobre o corpo dos outros, não simplesmente para que façam o que se quer, mas para que operem como se quer, com as técnicas, segundo a rapidez e a eficácia que se determina. A disciplina fabrica assim corpos submissos e exercitados, corpos 'dóceis'. A disciplina aumenta as forças do corpo (em termos econômicos de utilidade) e diminui essas mesmas forças 'em termos políticos de obediência' (FOUCAULT, 2005, p. 119).

$\mathrm{Na}$ concepção do autor, as instituições educacionais - Estado, escola, religião, hospital, prisão, família etc. - não funcionam apenas como espaços de circulação de corpos. Todas essas instituições, se estruturam como espaços/tempos de (re)produção e educação dos corpos; buscando a manutenção de uma ordem desejada. A partir do que expõe Foucault, arriscamos dizer que os aplicativos constituiriam espaços digitais, projetados estrategicamente para a educação e produção de corpos. Nessa perspectiva, “[...] o Ser dobrado não é uma questão de corpos, mas de locais fabricados" (ROSE, 2001, p. 50) e esses locais atuam pedagógica e politicamente para a transmissão de um conjunto de técnicas corporais, gestos, hábitos, modos culturais de se comportar e de utilizar o corpo (MAUSS, 2015).

Contudo, da segunda metade para o fim do século XVIII, Foucault atenta para a emergência de uma outra tecnologia de poder, que incorporara a essas técnicas disciplinares e individualizantes a população, os acontecimentos da vida das pessoas, a biologia desses corpos. Com a entrada do corpo biológico no campo da política e do Estado em meados do século XVIII, uma série de técnicas de poder centradas na vida dos homens foram, então, inauguradas, criando estratégias que passaram de individualizantes para massificadoras 
tornando-se, assim, uma biopolítica (FOUCAULT, 2005). Em suma, a biopolítica constitui-se em uma tecnologia dirigida à multiplicidade dos homens na medida em que forma uma massa global, impactada pelos processos que são próprios da vida dos indivíduos, como nascimento, morte, produção e a doença.

Em vista disso, o desenvolvimento da biopolítica objetiva, como bem salientou Foucault (2013), intervir em fenômenos sociais, de modo a controlá-los, estimulá-los ou reduzi-los. Como exemplo, a elaboração de ferramentas estatísticas que permitem acompanhar as taxas de natalidade, de mortalidade, de longevidade; a expansão de instituições de assistência social direcionadas para idosos e enfermos que estão incapacitados de trabalhar; a criação de planos de saúde, seguros de vida, de poupanças e de aposentadoria. Assim, a biopolítica considera a gerência de nascimentos e de mortes; as taxas de natalidade; o acompanhamento da expectativa de vida das populações e outras formas de controle social. Deste modo, destaca Foucault:

[...] sem dúvida, o biológico reflete-se no político; o fato de viver não é mais esse sustentáculo inacessível que só emerge de tempos em tempos, no caso da morte e da fatalidade: cai, em parte, no campo do controle do saber e de intervenção do poder (FOUCAULT, 2013, p. 155)

Para o autor, a existência biológica dos indivíduos passa a ser cuidada e fomentada. Para isso, “[...] o poder se situa e [se] exerce ao nível da vida, da espécie, da raça e dos fenômenos maciços de população" (FOUCAULT, 2013, p. 149-150), gerindo e organizando a vida e as forças produtivas populacionais: "[...] é sobre a vida e ao longo de todo o seu desenrolar que o poder estabelece seus pontos de fixação" (FOUCAULT, 2013, p. 151). Logo, Foucault $(2008 ; 2013)$ entende o Biopoder enquanto uma tecnologia de poder sobre a vida dos indivíduos e da população, e este por sua vez atua em dois níveis: Um centrado no corpo (individualizante) e outro centrado no controle da vida dos indivíduos em seu conjunto, em termos de população.

Ora, visto por esse ângulo, o investimento sobre o corpo valoriza a vida, que precisa ser mantida e prolongada. A partir da leitura de Foucault, isso foi possível graças a implementação dos dispositivos de biopoder.

Nikolas Rose (2013), ao fazer uma reflexão do presente a respeito da biopolítica - a política da própria vida do século XXI - se empenha em analisar as novas nuances decorrentes da forma de gerência da vida atualmente, as-diferenciando das analisadas por Foucault. Para o autor, as estratégias biopolíticas passaram ao largo do século XX, mais especificamente em sua parte final, a adquirir diferente e renovados contornos sobre a 
população. Nikolas Rose salienta que dentre os temas dessa política contemporânea da vida, alguns já são conhecidos, porém outros são novos; como exemplo dessa novidade, ele cita as mudanças ocorridas nas racionalidades e nas tecnologias de governo. Na sua concepção, “[...] principalmente nas transformações no fornecimento de segurança, bem-estar e saúde" (ROSE, 2013, p. 16). Segundo ele, dentre os demais campos, essas modificações foram mais eloquentes no campo da saúde:

[...] os seres humanos chegam a experimentar a si mesmos de novas maneiras como criaturas biológicas, como si-mesmos biológicos, sua existência vital torna-se foco de governo, alvo de novas formas de autoridade e de expertise, um campo altamente catéxico para o conhecimento, um território em expansão para a exploração bioeconômica, um princípio organizador de ética e uma aposta em uma política de vida (ROSE, 2013, p. 17).

Dentre os processos responsáveis por instituir as novas bases da biopolítica contemporânea abordados por Rose, nos interessa pontuar rapidamente um dos cinco caminhos, que para ele, estão passando por mutações significativas: as economias de vitalidade. Sobre isso, o autor menciona que:

[...] Quinto, economias de vitalidade. Fortalecidos pela busca de biovalores, novos laços se formaram entre verdade e capitalização, a busca do valor de acionista e o valor humano investido na esperança da cura e da otimização. Novo espaço econômico foi delineado - a bioeconomia - e nova forma de capital - biocapital. Antigos atores, tais como corporações farmacêuticas, foram modificados em sua relação com a ciência, de um lado, e com o mercado de valores, de outro. Novos atores, tais como as empresas iniciantes de biotecnologia, surgiram, frequentemente buscando enfatizar sua responsabilidade social corporativa e conciliando-se, de várias maneiras, com as formas de cidadania e expertise. A vida em si mesma tornou-se maleável a essas novas relações econômicas, enquanto a vitalidade é decomposta em uma série de objetos distintos e discretos - que podem ser isolados, delimitados, armazenados, acumulados, mobilizados e permutados, aos quais se pode atribuir discreto valor, comerciados ao longo do tempo, do espaço, gêneros, contextos, empresas - a serviço de muitos objetivos distintos. No processo, um novo campo geopolítico tomou forma, e a biopolítica tornou-se inextricavelmente entretecida à bioeconomia (ROSE, 2013, p. 20).

Como anunciado por Rose, existe atualmente uma economia que se volta e abarca a vida, que é responsável pela gestão e geração de um biocapital, este último proveniente dos avanços tecnológicos e biomédicos. O corpo enquanto um território, é lugar de demarcações, uma topografia (topos) da política, espaço de identificação por meio de características observáveis, bem como por linguagens que dão uma capacidade de representação. Por essa 
razão os estudos de Foucault e as contribuições de Rose são importantes para compreensão do corpo enquanto um lugar onde os dispositivos de poder atuam.

Os aplicativos móveis de musculação, enquanto dispositivos biopolíticos são responsáveis por gerir não só o corpo do usuário (que se mantem subordinado ao programa do desenvolvedor, que controla os corpos via relatórios que são exigidos pelo próprio aplicativo) mas pela gestão do corpo do usuário na condição de aluno e aprendiz da prática, que assumindo tal função parece "obrigado a se manter passivo" e apenas seguir o programa. O aplicativo é quem comanda, o usuário/aluno obedece. Ele dita o tempo, o início e o fim da atividade. Seguindo as ordens do aplicativo "Exercícios em Casa - Sem equipamentos", durante o uso:

Durante as aulas, o usuário deve reproduzir os movimentos mostrados na tela. Uma contagem regressiva mostra por quanto tempo o usuário deve fazer aquele exercício, com uma contagem regressiva em texto e em áudio. $\mathrm{O}$ app também mostra o tempo de descanso entre uma atividade e outra (GOOGLE PLAY, 2021b)

O aplicativo "BodBot", diz controlar a rotina do usuário, incluindo até mudanças inesperadas que possam vir a ocorrer e que impossibilite por vários motivos o aluno a cumprir o planejado, como: ter uma noite de insônia, não cumprir a atividade por conta de alguma limitação física etc. Para os desenvolvedores do aplicativo, o aluno não deve se preocupar com nada, cabe ao aplicativo cuidar de tudo "[...] o BodBot cuida dessas mudanças para você" (GOOGLE PLAY, 2021a).

o agenciamento do espaço corresponderá ao problema da organização de um "meio" que permita a circulação das coisas e das pessoas. A normalização, por sua vez, irá se referir aos mecanismos de regulação que atuam sobre os processos gerais da vida. E o corpo a ser singularizado como objeto e sujeito dos mecanismos de poder é o corpo coletivo das populações (FONSECA, 2011, p. 242).

Essa homogeneidade da ação dos dispositivos está explícita, inclusive, nos argumentos usados na publicidade dos mesmos nas plataformas onde estão disponíveis. Para os usuários, os desenvolvedores dizem que o-motiva a alcançar as suas metas de saúde e fitness, “[...] o BodBot usará cada gota do seu suor para ajudar você a obter os resultados que deseja" (GOOGLE PLAY, 2021a). No caso do "Exercícios em Casa - Sem Equipamentos", o discurso segue na mesma linha apelativa, "[...] faça nossos exercícios e você notará uma mudança em seu corpo em apenas algumas semanas" (GOOGLE PLAY, 2021b). O apelo é: "invista em saúde, no entanto as empresas desenvolvedoras dos aplicativos estariam 
verdadeiramente preocupadas com a saúde dos usuários? Vale a reflexão, sobre o que essas empresas entendem por "saúde/saudável”.

Tendo como referência essa compreensão sobre a tecnologia política do corpo, sobre a analítica dos poderes e sobre a biopolítica indagamos como se estabelece a relação de verdade entre o exercício e a saúde e também como sobre como é possível compreender os estilos de vida nesse processo de constituição dos sujeitos, que nunca termina de se completar e que transita por modalidades de asujeitamento e resistência (NÓBREGA, 2011, p. 410)

Com relação ao padrão de corpo comercializado, este parece se encaixar no que elas denominam de "bom corpo". O aplicativo "Exercícios em casa - Sem equipamentos", ressalta que não é porque a atividade dura apenas alguns minutos que o usuário não alcançara "seus objetivos", pois seguindo a rotina planejada no aplicativo, “[...] irá ajudá-lo a conseguir a barriga tanquinho em casa" (GOOGLE PLAY, 2021b).

Esses aplicativos evidenciam o controle sobre a vida e os corpos dos usuários e geram dados para o desenvolvimento de novas estratégias de domínio e manutenção do biopoder, tendo em vista que eles capturam os hábitos narrados dos depoimentos extraídos dos usuários.

Portanto, a pluralidade de agendas e interesses que integram as plataformas que divulgam esses aplicativos de educação e monitoramento corporal não se relaciona somente com as interfaces de visualização de dados e os objetos que carregam consigo. Juntos, os aplicativos, os dados e os corpos conformam uma rede ampla de entidades - empresas, algoritmos, servidores, planos etc.- que produzem experiências corporais enquanto fonte de valor financeiro e berço de testes para o refinamento dos sistemas de controle, ou seja, agem como dispositivos biopolíticos. Como afirmamos anteriormente, estes aplicativos na condição de dispositivos biopolíticos, instauram métodos específicos baseados em prescrições digitais que tem por objetivo modelar o comportamento mediante o acesso detalhado às informações sobre os hábitos e o desempenho físico dos corpos, tendo em vista um biocapital para a manutenção da rede de controle.

\section{Considerações finais}

Este ensaio tentou demostrar como os aplicativos de musculação, apoiados no discurso de "vida saudável" e "conhecimento e controle de si" agem como dispositivos biopolíticos de educação do corpo disseminando discursos políticos e sentidos estéticos. Para sustentar tal 
pressuposto utilizamos como pano de fundo dois aplicativos" "BodBot Personal Trainer: Instrutor de treinamento" e "Exercícios em Casa - Sem Equipamentos". "Como dito, ao longo do ensaio, buscamos a compreensão dos aplicativos como gestores de comportamentos, ou seja, enquanto instrumento de educação do corpo. Neste sentido, observamos que os aplicativos analisados extraem da atitude corporal os "fazeres que produzem saberes" que, por sua vez, irão atualizar os modos e os corpos dos usuários. Constatamos de que esses dispositivos têm poderes apelativos que visam à homogeneização das condutas, à normalização e o governo de si. Ou seja, grosso modo, são dispositivos biopolíticos.

Arriscamos também afirmar que os aplicativos são experimentos, instrumentos epistemológicos concebidos para conhecer através da experiência de quem usa. Assim, por intermédio das experiências e rotinas de monitoramento, os próprios desenvolvedores dos aplicativos e os usuários aprendem sobre os corpos ensinando-os a incorporar ao "se mover". "No exercício, nas práticas corporais, os sujeitos podem encontrar espaços de produção de tecnologias de si que permitam um trabalho sobre o corpo e a alma" (NÓBREGA, 2011, p. 412). Nesse percurso, os modos de "adquirir um corpo" revelam-se, ao mesmo tempo que se desvelam também procedimentos metodológicos e formas alternativas de encarnar e controlar o corpo através dos dados digitais. É o Nicolas Rose denomina de “[...] montagens híbridas de saberes, instrumentos, pessoas, sistemas de julgamento, edifícios e espaços, orientados, no nível programático, por certos pressupostos e objetivos sobre os seres humanos" (ROSE, 2001, p. 38).

Falar sobre o corpo "controlado via dispositivos biopolíticos" no atual cenário tecnológico é também tensionar algumas questões que se desdobram num projeto de "exaustão" e "retirada de potência" do corpo. "[...] os corpos não se formam mais, mas cedem progressivamente a toda sorte de deformações.... É como se tocássemos a própria definição do corpo: o corpo é aquele que não aguenta mais, aquele que não se ergue mais" (LAPOUJADE, 2002, p. 82). O autor, fala de um corpo "esmorecido", "prostrado" diante da vida; um corpo diminuído, controlado e preso a amarras que lhes são impostas por modelos estrategicamente desenvolvidos para a manutenção dos poderes através dos mais variados dispositivos biopolíticos.

${ }^{9}$ Selecionamos estes aplicativos por terem a "melhor avaliação" segundo usuários na plataforma do Google Play Store. 


\section{REFERÊNCIAS}

AGAMBEN, G. O que é o contemporâneo? E outros ensaios. Chapecó: ARGOS, 2009.

BÁRTOLO, J. Corpo e sentido: estudos intersemióticos. Portugal/Covilhã: Livros LabCom, 2007.

CRISORIO, R. Actividad física versus prácticas corporales. In: E. Galak y E. Gambarotta (Eds.). Cuerpo, educación y política: Tensiones epistémicas, históricas y prácticas. Buenos Aires, 2015.

ESPOSITO, R. Bios: biopolítica e filosofia. Trad. Wander Melo Miranda. Belo Horizonte: Editora UFMG, 2017.

FONSECA, M. A. Entre a vida governada e o governo de si. In: ALBUQUERQUE JÚNIOR, D. M.; VEIGA-NETO, A.; SOUZA FILHO, A. (org.). Cartografias de Foucault. 2 ed. Belo Horizonte: Autêntica Editora, 2011. p. 241-252.

FOUCAULT, M. História da Sexualidade I: a vontade de saber. 23. ed. Rio de Janeiro: Edições Graal, 2013.

FOUCAULT, M. Segurança, território e população. São Paulo: Martins Fontes, 2008a.

FOUCAULT, M. Nascimento da biopolítica. curso dado no Collège de France (1978-1979). Trad. Eduardo Brandão São Paulo: Martins Fontes, 2008b.

FOUCAULT, M. Vigiar e Punir: história da violência nas prisões. Petrópolis, RJ: Vozes, 2005.

GALAK, E. Construir el cuerpo: cuatro consideraciones epistemo-metodológicas y tres metáforas para pensar el objeto de estudio 'cuerpo'. Poiésis: Revista do Programa de PósGraduação em Educação da UNIVALI, Tubarão, v. 8, n. 14, p. 348-364, jul./dez. 2014. Disponível em: http://www.portaldeperiodicos.unisul.br/index.php/poiesis/article/view/2294. Acesso em: 03 set. 2021.

GALAK, E. La curricularización del cuerpo. In: CRISORIO, R.; ESCUDERO, C. (org.). Educación del cuerpo: currículum, sujeto y saber. La Plata, Argentina: Editora da Universidad Nacional de La Plata, 2017. p. 191-198.

GOMES, I. M. Corpo, consumo e bioidentidades: trajetória de pesquisa e perspectivas analíticas na formação do indivíduo saudável. Revista Tempos e Espaços em Educação, v. 12, n. 28 , p. 127-140, jan. 2019.

LAPOUJADE, D. O corpo que não aguenta mais. In: LINS, D.; GADELHA, S. (org.). Nietzsche e Deleuze: Que pode o corpo. Rio de Janeiro, 2002. p. 81-90.

LUPTON, D. Apps as Artefacts: Towards a Critical Perspective on Mobile Health and Medical Apps. Societies, n. 4, p. 606-622, 2014. Disponível em: https://www.mdpi.com/2075-4698/4/4/606/htm. Acesso em 29 ago. 2021. 
LUPTON, D. M-health and health promotion: The digital cyborg and surveillance society. Social theory e health, v. 10, n. 3, p. 229-244, 2012. Disponível em:

https://www.researchgate.net/publication/263327941_M-

Health_and_Health_Promotion_The_Digital_Cyborg_and_Surveillance_Society. Acesso em: 27 ago. 2021.

MAUSS, M. As Técnicas Corporais. In: MAUSS, M. Sociologia e Antropologia. 2. ed. Trad. Paulo Neves. São Paulo: COSAC NAIFY, 2015. p. 397-420.

MILNER, J-C. Por una política de los seres hablantes: breve tratado político II. Olivos: Grama Ediciones, 2013.

NASCIMENTO, H. J.; MARTINS, H. G.; VICTER, E. F. Aplicativos para dispositivo móvel: entendendo o conceito de função matemática. In: CONGRESSO INTERNACIONAL DA ASSOCIAÇÃO BRASILEIRA DE EDUCAÇÃO A DISTÂNCIA, 19., 2013, Duque de Caxias. Anais [...]. Duque de Caxias, 2013.

NÓBREGA, T. P. O exercício dos corpos na cidade: o espaço, o tempo, o gesto. In: ALBUQUERQUE JÚNIOR, D. M.; VEIGA-NETO, A.; SOUZA FILHO, A. (org.). Cartografias de Foucault. 2. ed. Belo Horizonte: Autêntica Editora, 2011. p. 407-418.

GOOGLE PLAY. BodBot Personal Trainer: Instrutor de treinamento. 2021 a. Disponível em: https://play.google.com/store/apps/details?id=com.bodbot.trainer\&hl=pt_BR\&gl=US. Acesso em: 30 ago. 2021.

GOOGLE PLAY. Exercícios em casa: Sem equipamentos. 2021b. Disponível em: https://play.google.com/store/apps/details?id=homeworkout.homeworkouts.noequipment\&hl= pt_BR\&gl=US . Acesso em: 30 ago. 2021.

ROSE, N. A política da própria vida: biomedicina, poder e subjetividade no século XXI. São Paulo: Paulus, 2013.

ROSE, N. Como se deve fazer a história do eu? Educação e realidade, vol. 26, n. 1, 2001, p. 33-57. Disponível em: https://seer.ufrgs.br/educacaoerealidade/article/view/41313. Acesso em: 03 set. 2021.

SANT'ANNA, D. B. É possível realizar uma história do corpo? In: SOARES, C. L. (org). Corpo e História. Campinas, SP: Autores Associados, 2001.

VAZ, A. F. Da polifonia do corpo à multiplicidade de sua educação. Perspectiva - Revista do Centro de Ciências da Educação, Florianópolis, v. 21, n. 1, p. 7-11, jan./jun. 2003. Disponível em: https://periodicos.ufsc.br/index.php/perspectiva/article/view/10195. Acesso em: 23 ago. 2021.

WHO. World Health Organization. mHealth: new horizons for health through mobile technologies: based on the findings of the second global survey on ehealth. Geneva: 2011. (Global observatory for eHealth series, 3). Disponivel em: https://apps.who.int/iris/bitstream/handle/10665/44607/9789241564250_eng.pdf?sequence=1 \&isAllowed=y. Acesso em: 30 ago. 2021. 


\section{Como referenciar este artigo}

SOARES, C.; RIBEIRO, F. S.; ZOBOLI, F. Aplicativos de musculação como dispositivos biopolíticos de educação do corpo. Revista on line de Política e Gestão Educacional, Araraquara, v. 25, n. 3, p. 2475-2492, set./dez. 2021. e-ISSN:1519-9029. DOI: https://doi.org/10.22633/rpge.v25i3.15467

Submetido em: 16/09/2021

Revisões requeridas em: 13/10/2021

Aprovado em: 17/11/2021

Publicado em: 08/12/2021 